\title{
Vitronectin (serum spreading factor): its localisation in normal and fibrotic tissue
}

\author{
J T REILLY, J R G NASH* \\ From the University Departments of Haematology, and * Pathology, Royal Liverpool Hospital, Liverpool
}

SUMMARY The distribution of vitronectin and fibronectin in normal and fibrotic tissue was directly compared using indirect immunofluorescence. Both glycoproteins were ubiquitiously localised to loose connective tissue. Vitronectin, unlike fibronectin, was not detected in basement membranes, in normal renal glomeruli, or around smooth muscle cells of both musculares mucosae and propria of the gastrointestinal tract. The presence of vitronectin could not be shown in washed permeabilised platelets. Vitronectin was very much increased in reactive and fibrotic tissue, as was fibronectin. This was observed in lymph nodes affected by both nodular sclerosing Hodgkin's disease and by metastatic carcinoma as well as in myelofibrotic bone marrow and sclerotic glomeruli. These findings suggest that vitronectin may have an important role in the processes of inflammation and repair.

Vitronectin, also known as serum spreading factor and $\mathrm{S}$-protein, is a glycoprotein that promotes the attachment and spreading of a variety of epithelial cells and fibroblasts in vitro. ${ }^{1-3}$ It is an $\alpha$-globulin ${ }^{1}$ that has been isolated in the form of two non-covalently associated polypeptides with molecular weights of 65000 and 75000 . Like fibronectin, ${ }^{4}$ another adhesive glycoprotein, vitronectin has been localised to the extra-cellular matrices of various tissues, ${ }^{3}$ in addition to being associated with platelets ${ }^{5}$ and circulating in plasma at a concentration of $250-300 \mu \mathrm{g} / \mathrm{ml} .^{6}$ Biologically important quantities are also present in amniotic fluid and urinary protein. It is, however, biochemically, immunologically, and functionally distinct from fibronectin as well as from laminin and chondronectin. Vitronectin interacts with several substances including heparin, ${ }^{7}$ glycosaminoglycans, ${ }^{8}$ collagen' and glass.'

The function of plasma vitronectin is complex and involves regulation of both the complement and coagulation systems. Podack and Miller have shown that vitronectin binds to the terminal components of the complement system ( $\mathrm{C} 5 \mathrm{~b}-9)$, thereby preventing complement mediated cell lysis. ${ }^{10}$ Vitronectin also binds to heparin and neutralises its anticoagulant activity in the inhibition of coagulation factors by antithrombin III." ${ }^{12}$ Recently vitronectin, like fibron-• ectin, has been shown to modulate the function of monocytes. ${ }^{13}$
The role and source of vitronectin in tissues is at present unknown. The localisation within mesenchymal tissues suggests a possible role in the attachment of cells to the extra-cellular matrix, and that the fibroblast is the cell of origin. In this study immunofluorescence techniques were used to localise vitronectin in normal and fibrotic human tissues and to compare its distribution with that of fibronectin.

\section{Material and methods}

Mouse monoclonal anti-human vitronectin was obtained from Calbiochem (681110) and mouse monoclonal anti-human fibronectin from ICN Biomedicals Ltd (FN15-63-640-1). Fluorescein isothiocyanate (FITC) conjugated goat anti-mouse IgG was obtained from Dakopatts. Antibodies were diluted (vitronectin 1:100, fibronectin 1:200, FITC conjugate $1: 10$ ) in phosphate buffered saline (PBS), $\mathrm{pH} 7 \cdot 4$, before use.

Most tissues used in this study were obtained from specimens sent for routine surgical histological examination. Where such material was unavailable fresh necropsy tissue was examined. Immunofluorescence staining was performed on sections of fresh frozen tissue, subsequently fixed in methanol for 20 minutes. Myelofibrotic bone marrow was processed as previously described. ${ }^{14}$ Fixed sections were washed twice for 10 minutes in PBS and treated with primary antibody for 30 minutes. The PBS washes were repeated before treatment for 30 minutes with conjugated antibody. After two washes in PBS the 


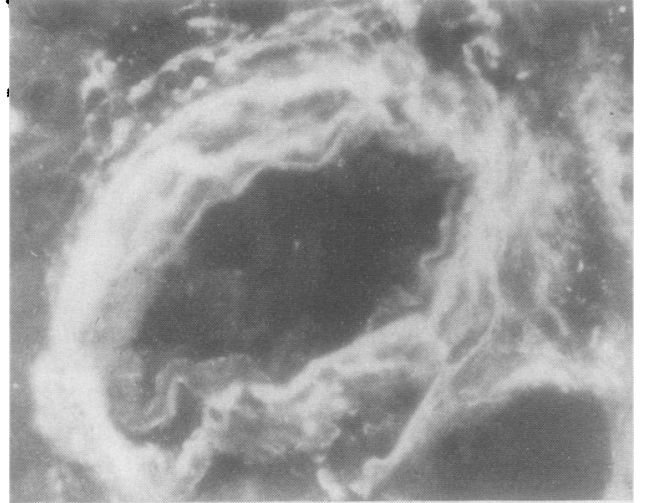

Fig 1 Renal artery. Vitronectin staining is present both subendothelially and in the elastic layers.

preparations were mounted using a solution containing equal volumes of glycerol and veronal-buffered ( 50 $\mathrm{mM}, \mathrm{pH} 8.6)$ sodium chloride $(100 \mathrm{mM})$. Fluorescence was examined using a Zeiss standard RA microscope fitted with an epifluorescence condenser and HBO $50 \mathrm{~W}$ mercury lamp. Platelets were prepared as described by Wencel-Drake et al. ${ }^{15}$ Photographs were taken with Kodachrome $\mathbf{4 0 0}$ film.
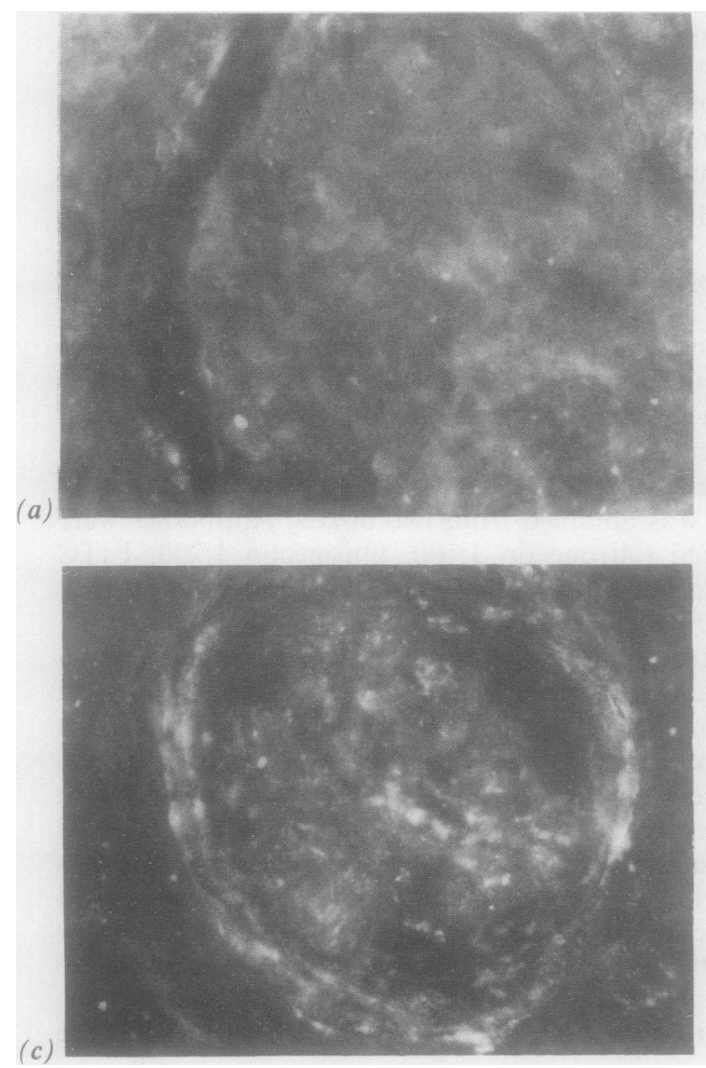

Substitution of primary antibody with non-immune mouse IgG or PBS produced negative staining. Negative results were also observed with inappropriate primary antibodies.

\section{Results}

Specific vitronectin immunoreactivity was shown in the loose connective tissue of all tissues examined. Strong positivity was noted in the supportive stroma of hepatic portal tracts and splenic cords as well as in the perimysium of skeletal and cardiac muscles. Vascular staining was located subendothelially, although it was most strong in the elastic layers (fig 1). Large vessels were more strongly reactive than capillaries. In contrast to fibronectin, vitronectin was not detected in basement membranes or around individual smooth muscle cells, being limited to the surrounding connective tissue septa. Normal renal glomeruli were consistently negative (fig $2 \mathrm{a}$ ), contrasting with the strong positivity of mesangial cells for fibronectin (fig $2 \mathrm{~b}$ ). Both glycoproteins were present in lymph nodes, being found as an intricate network throughout except in the germinal centres where only a few fibrils were present. Visceral capsular tissue stained intensely for both vitronectin and fibronectin.

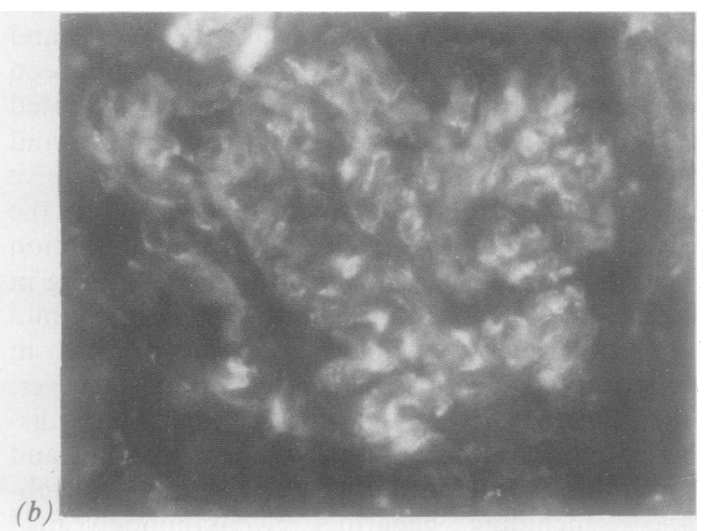

Fig 2 Kidney (a) Normal renal glomerulus. No vitronectin positivity is shown. (b) Normal renal glomerulus. Fibronectin staining is strongly positive in mesangial cells. (c) Benign nephrosclerosis showing glomerular positivity for vitronectin. 


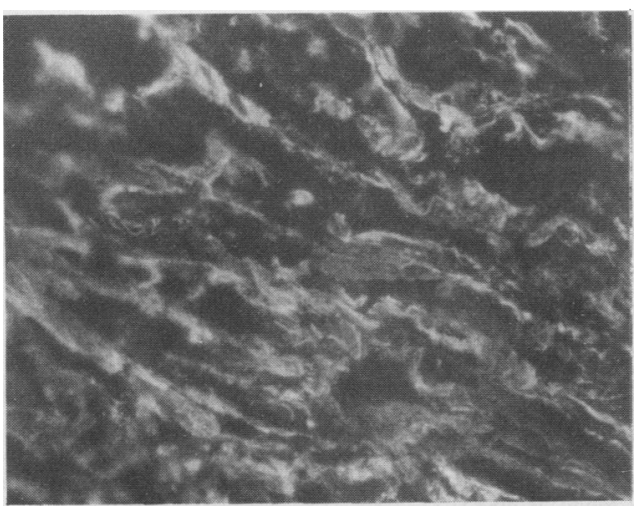

Fig 3 Lymph node infiltrated by metastatic carcinoma stained for vitronectin.

Vitronectin was present in sclerotic glomerular lesions in specimens affected by benign nephrosclerosis (fig 2c). Vitronectin positivity, like fibronectin, was also very much increased in reactive stromal tissue and in areas of fibrosis. This was shown in lymph nodes infiltrated by metastatic carcinoma (fig 3) and in areas affected by nodular sclerosing Hodgkin's disease. Myelofibrotic bone marrow was also shown to contain vitronectin.

Vitronectin was not detected in both permeabilised and non-permeabilised platelets. Fibronectin, however, was shown in the characteristic punctuate pattern due to $\alpha$ granule positivity in permeabilised cells.

\section{Discussion}

Vitronectin belongs to a family of adhesive glycoproteins that includes fibronectin, fibrinogen, and Von Willebrand factor. Vitronectin shares several functional similarities with fibronectin, despite the fact that except for the presence of the tripeptide Arg-GlyAsp (RGD) there is virtually no sequence homology between the two molecules. ${ }^{16}{ }^{17}$ This study confirms that vitronectin like fibronectin, is a major connective tissue glycoprotein occurring in loose connective tissue, blood vessel walls, and in the reticulin stroma of lymphatic tissue. ${ }^{18}$ Although the tissue distribution of vitronectin overlaps in general with fibronectin, the obvious differences suggest different roles for the two proteins. This is supported by the identification of distinct cell surface receptors for the RGD sequences in fibronectin and vitronectin ${ }^{19}$ and implies that cell adhesion specificities of matrices containing vitronectin are different from those containing fibronectin.

The increased deposition of vitronectin in fibrotic tissue is a novel finding and adds support to the in vitro studies that fibroblasts synthesise tissue vitronection.
We have previously reported a similar deposition of fibronectin in myelofibrosis and nodular sclerosing Hodgkin's disease. ${ }^{2021}$ Recently vitronectin was shown to have collagen binding site(s) which, unlike that of fibronectin, preferentially recognise(s) triple-helical collagen. ${ }^{9}$ This interaction is probably of relevance in vivo as vitronectin has been reported to co-distribute with collagens type I and III.' ${ }^{9}$ Further studies are in progress to determine the relation of vitronectin and the various collagen types in fibrotic tissue.

Barnes et al have published evidence for human platelet-associated vitronectin and postulated that it may have a role in platelet adhesion or aggregation. ${ }^{5}$ We have not been able to detect platelet vitronectin using indirect immunofluorescence. Fibronectin, however, was localised to platelet $\alpha$ granules as previously reported. ${ }^{22}$ The reason for this apparent discrepancy remains unclear.

The determination of vitronectin localisation in normal and pathological tissue is important for the understanding of its physiological function. The now reported immunoreactivity for fibrotic tissue, and the fact that vitronectin has a role in cell-substrate interaction, the coagulation and complement systems, as well as in monocyte function, suggests that it may be important in the pathophysiology of inflammation and repair.

We thank Professor P Johnson for use of his department's equipment and Miss $\mathbf{R}$ Boardman for secretarial help. This study was financially supported by the Mersey Regional Health Authority.

\section{References}

1 Holmes R. Preparation from human serum of an alpha-one protein which induces the immediate growth of unadapted cells in vitro. J Cell Biol 1967;32:297-308.

2 Barnes D, Wolfe R, Serrero G, McClure D, Sato G. Effects of a serum spreading factor on growth and morphology of cells in serum free medium. J Supramol Struct 1980;14:47-63.

3 Hayman EG, Pierschbacher MD, Orgren Y, Ruoslahti E. Serum spreading factor (vitronectin) is present at the cell surface and in tissues. Proc Natl Acad Sci USA 1983;80:4003-7.

4 Hynes RO, Yamada KM. Fibronectins; multifunctional modular glycoproteins. J Cell Biol 1982;95:369-77.

5 Barnes DW, Silnutzer J, See C, Shaffer M. Characterization of human serum spreading factor with monoclonal antibody. Proc Natl Acad Sci USA 1983;80:1362-6.

6 Shaffer MC, Foley TP, Barnes DW. Quantitation of spreading factor in human biologic fluids. J Lab Clin Med 1984;103: 783-91.

7 Barnes DW, Reing JE, Amos B. Heparin-binding properties of human serum spreading factor. J Biol Chem 1985;260:9117-22.

8 Akama T, Yamada K, Seno N, et al. Immunological characterisation of human vitronectin and its binding to glycosaminoglycans. J Biochem 1986;100:1343-51.

9 Gebb C, Hayman EG, Engvall E, Ruoslahti E. Interactions of vitronectin with collagen. J Biol Chem 1986;261:16698-703.

10 Podack ER, Muller-Eberhard HJ. Isolation of human S-protein and inhibitor of the membrane attack complex of complement. J Biol Chem 1979;254:9908-14. 
11 Preissner KT, Wassmuth R, Muller-Eberhard G. Physiochemical characterization of human S-protein and its function in the blood coagulation system. Biochem $J$ 1985;231:349-55.

12 Jenne D, Hugo F, Bhakdi S. Interaction of complement S-Protein with thrombin-antithrombin complexes: a role for the $S$-protein in haemostasis. Thromb Res 1985;38:401-12.

13 Parker CJ, Frame RN, Elstad MR. Vitronectin (S-protein) augments the functional activity of monocyte receptors for IgG and complement C3b. Blood 1988;71:86-93.

14 Pizzolo G, Chilosi M, Cetto GL, Fiore-Donati L, Janossy G. Immuno-histological analysis of bone marrow involvement in lymphoproliferative disorders. Br J Haematol 1982;50:95-100.

15 Wencel-Drake JD, Plow E, Zimmerman TS, Painter RG, Ginsberg MH. Immunofluorescent localization of adhesive glycoproteins in resting and thrombin-stimulated platelets. $\mathbf{A m}$ J Pathol 1984;115:156-64.

16 Pierschbacher MD, Ruoslahti E. Cell attachment activity of fibronectin can be duplicated by small synthetic fragments of the molecule. Nature 1984;309:30-3.

17 Suzuki S, Oldberg A, Hayman EG, Pierschbacher MD, Ruoslahti E. Complete amino-acid sequence of human vitronectin deduced from cDNA-similarity of cell attachment sites in vitronectin and fibronectin. EMBO 1985;4:2519-25.
18 Simonton SC, Basara ML, Barnes DW, Furcht LT. Distribution and immunolocalization of serum spreading factor in human tissue. Lab Invest 1985;52:63.

19 Pytela R, Pierschbacher MD, Ruoslahti E. A 125/115 kDa cell surface receptor specific for vitronectin interacts with the arginine-glycine-aspartic acid adhesion sequence derived from fibronectin. Proc Natl Acad Sci USA 1985;02:5766-70.

20 Reilly JT, Nash JRG, Mackie MJ, McVerry BA. Immunoenzymatic detection of fibronection in normal and pathological haematopoietic tissue. Br J Haematol 1985;59:497-504.

21 Reilly JT, Nash JRG, Mackie MJ, McVerry BA. Distribution of fibronectin and laminin in normal and pathological lymphoid tissue. J Clin Pathol 1985;38:849-54.

22 Zucker MB, Mosesson MW, Broekman MH, Kaplan KL. Release of platelet fibronectin (cold-insoluble globulin) from alpha granules induced by thrombin or collagen; lack of requirement for plasma fibronectin in ADP-induced platelet aggregation. Blood 1979;54:8-12.

Requests for reprints to: Dr J T Reilly, Department of Haematology, Northern General Hospital, Herries Road, Sheffield S5 7AU, England. 